Curr Protoc Bioinformatics. ; 58: 1.2.1-1.2.12. doi:10.1002/cpbi.27.

\title{
Searching Online Mendelian Inheritance in Man (OMIM): A Knowledgebase of Human Genes and Genetic Phenotypes
}

\author{
Joanna S. Amberger ${ }^{1}$ and Ada Hamosh \\ McKusick-Nathans Institute of Genetic Medicine, Johns Hopkins University School of Medicine, \\ Baltimore, MD 21287, Tel. 410-955-0313, Fax. 410-955-4999
}

\begin{abstract}
Online Mendelian Inheritance in Man (OMIM) at OMIM.org is the primary repository of comprehensive, curated information on genes and genetic phenotypes and the relationships between them. This unit provides an overview of the types of information in OMIM and optimal strategies for searching and retrieving the information. OMIM.org has links to many related and complementary databases providing easy access to exploring more information on a topic. The relationship between genes and genetic disorders is highlighted in this unit. The basic protocol explains searching OMIM both from a gene then clinical features perspective. Two alternate protocols provide strategies for viewing gene-phenotype relationships as a gene map table and clinical features as a Quick View or Side-by-Side format. OMIM.org is updated nightly and the MIMmatch service, described in the Support Protocol, provides a convenient way to follow updates to entries, gene-phenotype relationships, and collaborate with other researchers.
\end{abstract}

\section{Keywords}

OMIM; human genetic disorders; molecular genetics; disease gene discovery

\section{INTRODUCTION}

Online Mendelian Inheritance in Man (OMIM $\left.{ }^{\circledR}\right)$ is a continuation of Dr. Victor McKusick's Mendelian Inheritance in Man (MIM) (McKusick, 1998), a seminal medical genetics resource used primarily by physicians and other professionals interested in genetic disorders, by genetics researchers, and by advanced students in science and medicine. It provides concise textual information based on the peer-reviewed biomedical literature on over 15,500 genes, 26,200 allelic variants, and 7,800 genetic phenotypes. In addition, OMIM.org provides tabular views of phenotype-gene relationships (gene map), overviews of clinical features of phenotypes (clinical synopses), phenotypic series, and a convenient way to follow updates and collaborate (MIMmatch). All entries in OMIM contain extensive targeted

\footnotetext{
1 joanna@peas.welch.jhu.edu.

Internet Resources

http://omim.org

The OMIM Web site.

http://omim.org/help/faq

Frequently asked questions (FAQ) about OMIM
} 
links to external data resources. The overall structure of OMIM is shown in Figure 1.2.1 and illustrates the intersections of gene and phenotype information.

The Basic Protocol describes a basic text search and overview of the layout of search results. Alternate Protocol 1 explains searching the Gene Map to reveal unique displays of the intersection between gene and phenotype. Alternate Protocol 2 explains searching clinical information to display the Quick View and Side-by-Side views of the Clinical Synopses. The Support Protocol describes how to register for MIMmatch alerts.

\section{BASIC PROTOCOL: SEARCHING OMIM}

OMIM.org is the official website for OMIM information. It has been optimized to retrieve and display information from OMIM in a straightforward and clear manner. OMIM.org supports free-text and field-directed searches. Detailed help, example searches, and tips are available from every screen. The top of the OMIM home page (https://omim.org) shows the black menu bar that is common across all OMIM.org web pages. From this menu a user can always access Statistics, Download/API registration, Contact Us, MIMmatch access, Help/ FAQ, and Tips specific for the page (?). Statistics include the Update List of new and added entries, number of entries in OMIM, and number of phenotype-gene relationships cataloged by OMIM. Below the search box is access to advanced search pages, example searches, search help, and a tutorial.

\section{Necessary Resources}

Hardware-Any Internet-connected computer, tablet, or mobile device

Software-Up-to-date Web browsers such as Chrome, FireFox, Safari, Microsoft Explorer or Edge

\section{Performing an OMIM search for genes}

1. If, for example, you are interested in potassium channel genes, you can enter your search in a number of ways. For example, +potassium +channel (352 entries retrieved), $K C N^{*}$ (333 entries retrieved), or "potassium channel" (with quotes potassium and channel must appear as a phrase, 276 entries retrieved). Of note, entering potassium channel without qualifiers applies both Boolean AND and OR to the search. Entries satisfying the AND operator are given higher relevance (1,334 entries retrieved). OMIM searches are vocabulary enhanced to accommodate synonyms, British spelling, and user-selected thesaurus terms. Figure 1.2.2 shows an entry retrieval page for a search on +potassium +channel and is described below.

A. Blue buttons "Gene Map Table" and "Clinical Synopsis" to the right of the search box navigate the search results to the Gene Map display and Clinical Synopsis (see Alternate Protocols 1 and 2). If thesaurus terms are available for the search, they will be displayed below the search box. 
B. The text below the green line shows the total number of entries retrieved with that search; an option to expand the number of titles displayed; an option to download the search results, and retrieval navigation buttons.

C. Each entry in OMIM has a unique and stable MIM number. The MIM number has a prefix denoting whether the entry represents a gene or phenotype. A mouse-over reminds the user what they mean. The number is followed by the preferred MIM title and symbol. Clicking on the title brings up the full display of that entry. Below the title is the cytogenetic location and genomic coordinates; clicking on either of them takes the user to that gene/locus in OMIM's gene map or in UCSCs Genome Browser.

D. Colored triangles precede links to reveal on-page information and access to Gene-phenotype/Phenotype-gene Relationships, ICD+codes, Phenotypic series, and Links (opened for entry 600937). ICD+ and Phenotypic series links will not appear in gene entries. Access to this information is also present on the entry full view.

2. Clicking on the title for 176260 opens the entry full view for this gene (Figure 3 ). Note that the search terms are highlighted, and there is a green bar next to the Description paragraph denoting information that has been changed or added in the last 3 month. Highlights and change bars can be toggled off by selecting the option to the right of the search box.

A. Following the number and preferred title are alternative names that may have been given to the entry. The HGNC-approved gene symbol display and link are above the mapping information links and Gene-Phenotype relationship table.

B. Left of the title is the entry navigation Table of Contents. Selecting the heading takes the user directly to that section in the entry. Note that Allelic Variants are listed in a gene entry and can be viewed as descriptive text or in a Table View (Figure 1.2.4). Both versions have links, when available, to dbSNP, ExAC, and ClinVar.

C. To the right of the title are External Links. The topically organized pulldown menus in this stack contain links to over 55 resources including genome browsers, DNA and protein sequence databases, model organism databases, pathway database, etc. Each link takes the user directly to the relevant information in that resource.

D. The plus sign at the end of text paragraphs takes the user to articles in PubMed that are related to the citation(s) in the MIM entry paragraph. This is an easy way to find additional articles that may be available on a specific topic. 


\section{Performing an OMIM search for phenotypes (including disorders) or clinical features}

1. Information in a phenotype entry is different from that in a gene entry. Organizationally, each phenotype in a unique phenotype-gene relationship has its own OMIM entry and number. Clinical features in an entry are specific to that phenotype-gene relationship. To show how a class of related phenotypes lies across the genome, OMIM has Phenotypic Series. Users can search by disorder name or clinical features. For example, starting at the OMIM.org home page, search on hypogonadism and microcornea. Optional thesaurus terms related to hypogonadism (e.g., hypogenitalism, micropenis, small testis, etc.) are displayed under the search box that could be selected to further broaden a search. For the purposes of this protocol, select 600118 by clicking on the title, Warburg Micro syndrome 1 (Figure 1.2.5).

A. The ICD+ link shows the available disease identifiers. The External Links have robust Clinical Resources (shown), Animal Model, and Cell Lines sections. These links appear only if there is information in the external resource that is relevant to the MIM entry.

B. The Clinical Synopsis (a feature-based list) and Phenotypic Series links can display contents in-page (down triangle, shown here) or in a new page (main button).

C. If the user is a MIMmatch member, MIMmatch options will be displayed below the Table of Contents to the left of the entry. The user has options to follow updates to the entry or share interest. This entry has 15 individuals sharing their interest. The link provides details and a way to share contact information.

D. The Phenotypic Series shows the genetic heterogeneity of Warburg Micro syndrome (Figure 1.2.6).

\section{GUIDELINES FOR UNDERSTANDING ENTRY STRUCTURE AND CONTENT}

[Copy Editor: Rather than having one Guidelines section following the last protocol, the authors have included protocol-specific guidelines after each protocol. CP style can accommodate this.]

\section{Number}

Each OMIM entry is given a unique and stable six-digit number based on the chromosomal location. Autosomal entries start with a 1, 2 or 6, X-linked entries start with a 3, Y-linked with a 4 , and mitochondrial with a 5 . Numbers that start with a 1 or 2 do not refer to a mode of inheritance.

MIM numbers are preceded by a prefix:

An asterisk (*) before an entry number indicates a gene. 
A number symbol (\#) before an entry number indicates that it is a descriptive entry, usually of a phenotype, and does not represent a unique locus. The reason for the use of the number symbol is given in the first paragraph of the entry. Discussion of any gene(s) related to the phenotype resides in another entry(ies) as described in the first paragraph.

A plus sign (+) before an entry number indicates that the entry contains the description of a gene of known sequence and a phenotype.

A percent sign (\%) before an entry number indicates that the entry describes a confirmed mendelian phenotype or phenotypic locus for which the underlying molecular basis is not known.

No symbol before an entry number generally indicates a description of a phenotype for which the mendelian basis, although suspected, has not been clearly established or that the separateness of this phenotype from that in another entry is unclear.

A caret $\left({ }^{\wedge}\right)$ before an entry number means the entry was removed from the database or moved to another entry as indicated.

\section{Title}

Each entry has a "Preferred title" with symbol. Synonymous names and symbols that have been used in the literature are included as "Alternative title(s)". "Included titles" mark placement of information on a topic that does not warrant a separate entry (e.g., fusion genes).

\section{Text}

Information in the main text of an OMIM entry is put under standard headings (e.g., Description, Clinical Features, Cloning and Expression, etc.) that can be targeted in fielded searches (see online search help 1.5; https://omim.org/help/search\#1_5).

\section{Allelic Variants}

This section reports mutations and variations in the gene that are found to underlie a phenotype. OMIM includes only select variants. Criteria for inclusion include the first mutation to be discovered, high population frequency, distinctive phenotype, historic significance, unusual mechanism of mutation, unusual pathogenetic mechanism, and distinctive inheritance (e.g., dominant with some mutations, recessive with other mutations in the same gene). Most of the allelic variants represent disease-causing mutations. A few polymorphisms are included, many of which show a positive correlation with particular common disorders. Effective January 2013, based on a rigorous assessment of published reports, OMIM creates phenotype-gene relationships that are "established," "provisional," or of "unknown significance." An established relationship may be based on (1) the existence of multiple, unrelated individuals with pathogenic variants in the same gene; (2) variants that segregate with the phenotype in multiplex families; and/or (3) variants that occur de novo in a statistically significant number of individuals. Functional data and/or animal models support the causality but are not required. A provisional relationship may be based on (1) only one multiplex family reported to have variants in a single gene and the variants 
segregate with the phenotype in the family, and (2) there is supportive functional data such as in vitro enzyme activity, a comparable phenotype in a model organism experiment, or an animal model. In this case the gene-phenotype relationship is qualified by noting that the variant has been identified in only 1 family. In rare instances, a similar gene-phenotype relationship may be established on the basis of a single patient if there is robust supporting phenotype and functional data. A variant of unknown significance may be created if a report identifies only 1 patient or family and provides no supporting functional data.

\section{References}

All information in an OMIM entry is cited. The references are listed in alphabetical order in this section. There are links to PubMed and to the full text of the article, when available.

\section{ALTERNATE PROTOCOL 1: SEARCHING OMIM'S GENE MAP}

OMIM's Gene Map is a table of the genes and loci in OMIM organized by chromosome. OMIM currently has entries for over 15,500 genes and focuses on gene-phenotype relationships. The tabular format provides easy access to multiple gene-phenotype relationships in a single view. The table includes the cytogenetic location, genomic coordinates, gene/locus symbol and title, gene/locus MIM\#, comments, and homologous mouse gene. If there is a phenotype(s) associated with a gene/locus, there is a column for phenotype, the phenotype MIM\#, the inheritance mode, and the phenotype mapping key. Mousing over the number will display the definition of the key. A summary of the definitions are the following: (1) the disorder was positioned by mapping of the wildtype gene; (2) the disease phenotype itself was mapped; (3) the molecular basis of the disorder is known; (4) the disorder is a chromosome deletion or duplication syndrome. The following describes accessing the gene map table view of a standard search OMIM then restricting the view to genes with phenotypes and then a direct search of the gene map by genomic coordinates to show the phenotypes within a region.

\section{Necessary Resources}

Hardware-Any Internet-connected computer, tablet, or mobile device

Software-Up-to-date Web browsers such as Chrome, FireFox, Safari, Microsoft Explorer or Edge

\section{View phenotypes associated with a gene-based search}

1. Go to https://omim.org and type a gene symbol or words like "potassium channel" (with quotes) in the search box. Then select search.

2. From the retrieval entry page, select the Gene Map Table button to the right of the search box (Figure 1.2.2). This will display the search retrieval in table form in the Gene Map viewer.

3. Select the Phenotype Only Entries toggle to display only those entries from the search that have phenotypes (Figure 1.2.7). 


\section{Perform a genomic coordinate search}

1. Go to https://omim.org and select Gene Map from the advanced search options below the search box.

2. Type in a chromosome number followed by a genomic region (e.g., 18:23,234,12-43,221,000) or cytogenetic location (e.g., 18p11.3). The display will include all genes and loci in OMIM that are in or overlap the search region (Figure 1.2.8). The explanation of the phenotype mapping key and download options are displayed.

\section{ALTERNATE PROTOCOL 2: SEARCHING OMIM CLINICAL SYNOPSES}

Each OMIM phenotype entry has a clinical synopsis that contains a list of the salient clinical features described for the phenotype. These features are curated from the biomedical literature and are specific to unique gene-phenotype combinations. This protocol describes accessing the Clinical Synopsis Quick View format and the Side-by-Side viewer.

\section{Necessary Resources}

Hardware-Any Internet-connected computer, tablet, or mobile device

Software-Up-to-date Web browsers such as Chrome, FireFox, Safari, Microsoft Explorer or Edge

\section{Accessing the OMIM Clinical Synopsis quick view and side-by-side view}

1. Go to https://omim.org and type microcornea AND hypogonadism in the search box. Then select search.

2. From the entry retrieval page, select the Clinical Synopsis button to the right of the search box (see Figure 1.2.2).

3. Entries from the search with Clinical Synopses are displayed in the Quick View format. Mouse over the anatomical headings to view the features (Figure 1.2.9).

4. Check the box under the entry retrieval number to select the entries to compare side-by-side.

5. Click the Compare Selected button to reveal the selected synopses side-by-side (Figure 1.2.10). The display of an Elements of Morphology feature definition photo for brachycephaly is displayed.

\section{SUPPORT PROTOCOL 1: Registering for and using MIMmatch}

MIMmatch is a service available through OMIM.org that provides easy ways to stay up-todate and collaborate. MIMmatch users can (1) designate entries they wish to follow and to receive email alerts when the entries are updated; (2) find other researchers who may share their interest in certain entries; (3) receive a daily update on any new gene-phenotype relationships established in OMIM; and/or (4) save search queries. Your name will appear only to other MIMmatch users and only on those entries you designate. All MIMmatch 
alerts for a user are collected in a single email, and user's information is not shared without the user's consent.

\section{Necessary Resources}

Hardware—Any Internet-connected computer, tablet, or mobile device

Software-Up-to-date Web browsers such as Chrome, FireFox, Safari, Microsoft Explorer or Edge

1. Go to https://omim.org and select MIMmatch from the menu items on the black bar at the top of the page. Enter the required information on the entry form and click "create account". An email will be sent to you requiring you to activate the newly created account.

Note: MIMmatch options described below will not appear on the website unless you are logged into MIMmatch.

2. When you sign into MIMmatch from the MIMmatch option on the black bar at the top of every OMIM.org page, you will be taken to your MIMmatch dashboard page. From this page you can check the box to be notified of new gene-phenotype relationships and will see 3 tabs: (1)"MIM Entries Flagged" for following or sharing interest; (2) "Phenotypic Series Flagged" for following updates to phenotypic series; and (3) "Saved Searches".

3. Once you have established a MIMmatch account and are logged in, you can populate your "MIM Entries Flagged" when you search OMIM. For example, from a search of thypogonadism +microcornea, you can select "Notify me on update" or "Share my interest" by clicking on the MIMmatch link below the desired entry. You can view others who have chosen to share their interest on this entry from the "Others interested in this entry" link below the MIM titles on a search retrieval page (Figure 1.2.11). The MIMmatch options also appear below the Table of Contents in the full entry (Figure 1.2.3).

4. The "Save search" option supports an easy way to perform the same query of OMIM on a regular basis. A query can be saved by selecting "Save search" from the Options link to the right of the search box.

\section{SUPPORT PROTOCOL: Download and API}

From the Downloads link in the black bar, users can access mim2gene.txt, a tab-delimited file linking MIM numbers with NCBI Gene IDs, Ensembl Gene IDs, and HGNC Approved Gene Symbols. Access to additional OMIM data and the API is available after registration. The API is robust and includes the functionality of the website. Online help that is specific for API use is available under the Help menu option in the black menu bar at the top of the page. 


\section{COMMENTARY}

\section{Background Information}

OMIM entries are based on the peer-reviewed biomedical literature and are expertly curated into structured entries. These executive summaries are a great place to learn about genes and phenotypes, and users are encouraged to explore the copious links both within OMIM entries and to the many linked external resources. Should a user have additional questions about specific information in an OMIM entry, there are links directly to the source reference for further investigation and clarification. The knowledgebase is updated nightly, and the website is designed to display on desktop, tablet, and mobile devices.

\section{Acknowledgments}

This work is supported by NHGRI grant, 1U41HG006627.

\section{Literature Cited}

McKusick, VA. Online Mendelian Inheritance in Man: A Catalog of Human Genes and Genetic Disorders. 12. Johns Hopkins University Press; Baltimore, Maryland: 1998.

Amberger JS, Bocchini CA, Schiettecatte F, Scott AF, Hamosh A. OMIM.org: Online Mendelian Inheritance in Man (OMIM®), an online catalog of human genes and genetic disorders. Nucleic Acids Res. 2015; 43(Database issue):D789-98. [PubMed: 25428349]

Amberger J, Bocchini CA, Hamosh A. A new face and new challenges for Online Mendelian Inheritance in Man (OMIM). Hum. Mutat. 2011; 32:564-567. [PubMed: 21472891] 


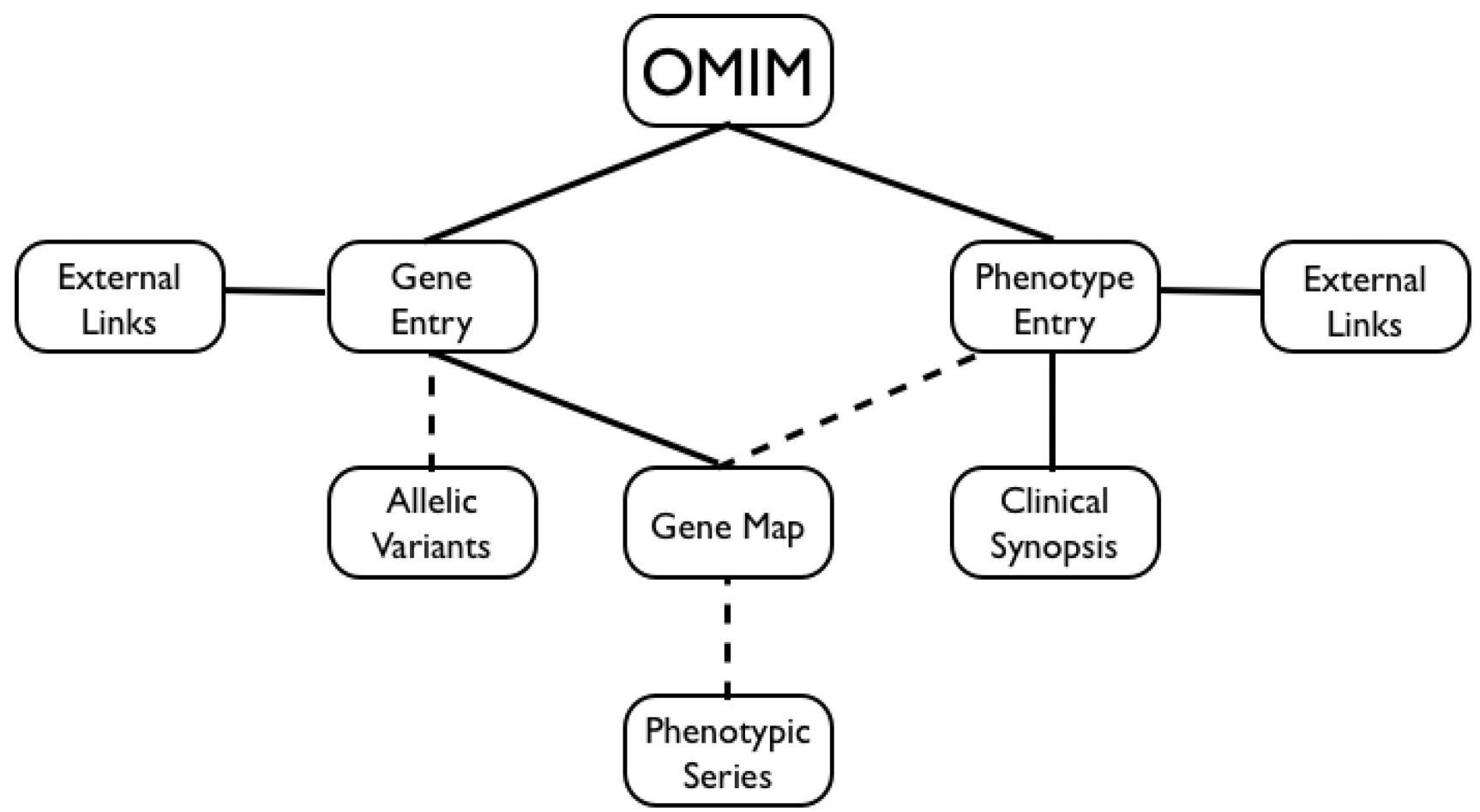

Figure 1.2.1.

Diagram of OMIM content. Dashed lines indicate that not all genes have allelic variants; not all phenotypes are mapped; and mapped phenotypes are not necessarily part of a Phenotypic Series. 
About Statistics - Downloads - Contact Us MIMmatch Donate - Help - 9

+potassium +channel

Q Options -

View Results as: Gene Map Table Clinical Synopsis

Display: $\nabla$ Hignights

Search: '+potassium +channel'

Results: 352 entries.

Show 100 | Download As - | «First | «Previous | Next , | Last »

1: 176260 . I Gene description NNEL, VOLTAGE-GATED, SHAKER-RELATED SUBFAMILY, MEMBER 1; KCNA1

Cytogenetic Iocation: Izp13.32, venomic coordinates (GRCh38): 12:4,909,906-4,918,255

Matching terms: potassium, channel

$\checkmark$ Cene-Phenotype Relationships $\gg$ Links

2: *600937. POTASSIUM CHANNEL, INWARDLY RECTIFYING, SUBFAMILY J, MEMBER 11; KCNJ11

Cytogenetic location: 11p15.1, Genomic coordinates (GRCh38): 11:17,385,245-17,389,330

Matching terms: potassium, channel

$\checkmark$ Gene-Phenotype Relationships $\mathbf{\nabla}$ Links

Links

Testing Cenome

Cene Ensembl Ensembl

Tests NCBI Map Viewer NCBI RefSeq

$\begin{array}{lll}\text { GTR } & \text { UCSC Genome } & \text { UCSC Cenom } \\ \text { NextGxDx } & \text { Browser } & \text { Browser }\end{array}$

Protein Gene Info

HPRD BioGPS

Browser

Atlas Protein Ensembl

Atlas

GeneCards

Gene
Ontology

KECG

Clinical Resources

Gene Tests

Genetics Hom

Reference

GTR
NextGxDx

UCSC

Variation 1000

Cenome

Clinvar

EXAC Beta

CWAS

Catalo

CWAS

Central
HGMD

HGMD
HGVS

NHLBI EVS

PharmCKB
Animal Models Cellular IMPC Pathways KOMP KEGC MGI Mouse Gene Reactome

$\mathrm{NCBI}$

HomoloGene

ZFin

Cytogenetic location: 11p15.5-p15.4, Genomic coordinates (GRCh38): 11:2,444,990-2,849,109

Matching terms: potassium, channel

Figure 1.2.2.

Search result page from a search of + potassium +channel at OMIM.org. Targeted links for entry 600937 are displayed by clicking the "Links" button below the entry title. The mouseover explanation of the MIM number prefix (in this case "Gene description") is also displayed. 


\section{About Statistics - Downloads - Contact Us Editor Admin - MiMmatch - Donate - Help - $\bullet$}

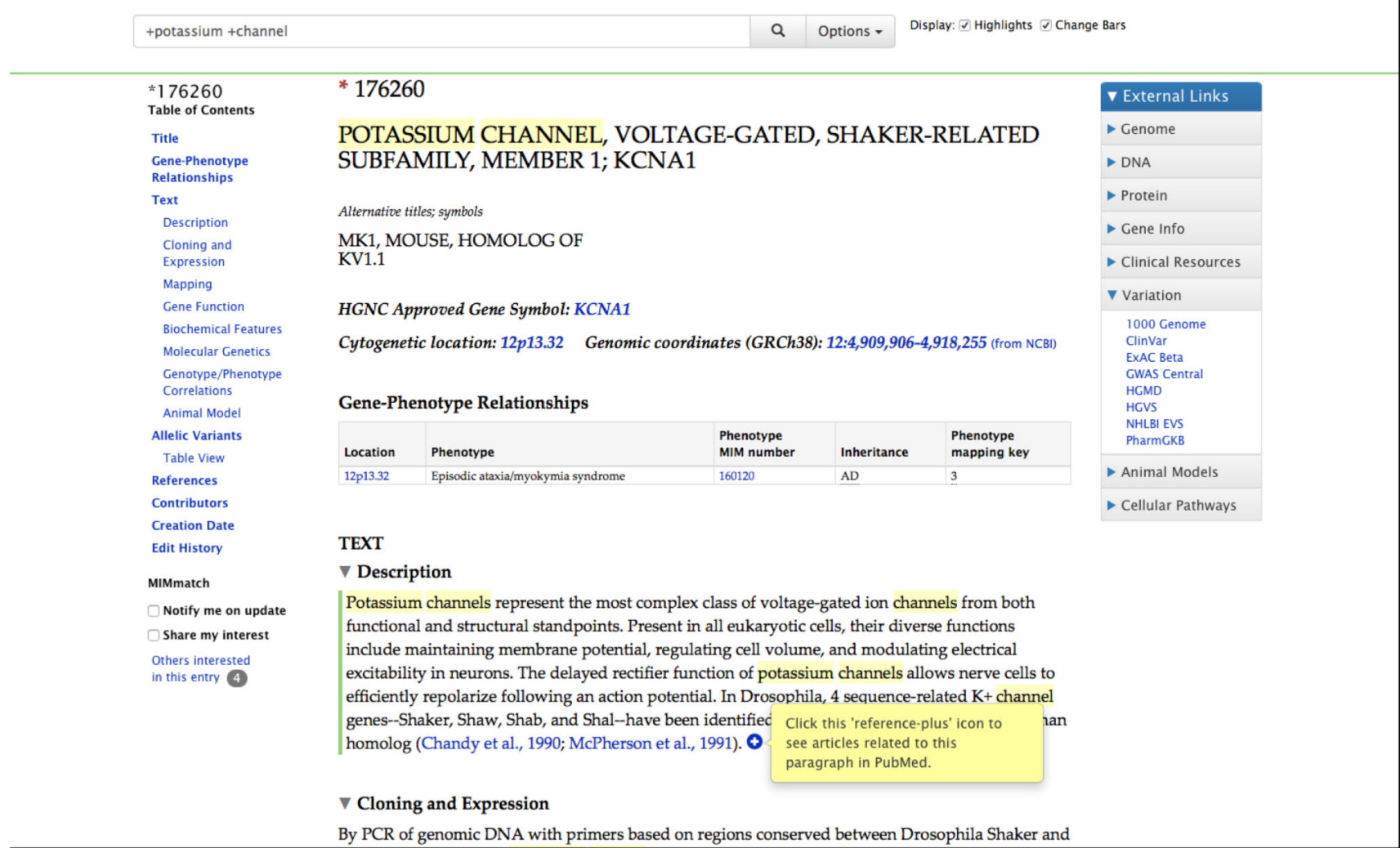

Figure 1.2.3.

Entry full view for 176260 displaying highlighted search terms, green entry change bar (left of description paragraph), and Reference Plus link. 
About Statistics - Downloads - Contact Us Editor Admin - MIMmatch - Donate - Help - 9

\begin{tabular}{|l|l|l}
\hline Search OMIM... & Q & Options - \\
\hline
\end{tabular}

176260

Download As =

POTASSIUM CHANNEL, VOLTAGE-GATED, SHAKER-RELATED SUBFAMILY, MEMBER

$1 ;$ KCNA1

Allelic Variants (15 Selected Examples) :

All ClinVar Variants

\begin{tabular}{|l|l|l|}
\hline Number & Phenotype & Mutation \\
\hline .0001 & EPISODIC ATAXIA, TYPE 1 & KCNA1, VAL408ALA \\
\hline .0002 & EPISODIC ATAXIA, TYPE 1 & KCNA1, ARG239SER \\
\hline .0003 & EPISODIC ATAXIA, TYPE 1 & KCNA1, VAL174PHE \\
\hline .0004 & EPISODIC ATAXIA, TYPE 1 & KCNA1, PHE249ILE \\
\hline .0005 & EPISODIC ATAXIA, TYPE 1 & KCNA1, PHE184CYS \\
\hline .0006 & EPISODIC ATAXIA, TYPE 1 & KCNA1, GLU325ASP \\
\hline .0007 & EPISODIC ATAXIA, TYPE 1 1 & KCNA1, THR226ALA \\
\hline .0008 & EPISODIC ATAXIA, TYPE 1 & KCNA1, VAL404ILE \\
\hline .0009 & EPISODIC ATAXIA, TYPE 1 & KCNA1, ILE177ASN \\
\hline .0010 & MYOKYMIA 1 & KCNA1, ALA242PRO \\
\hline .0011 & MYOKYMIA 1 & KCNA1, PRO244HIS \\
\hline .0012 & EPISODIC ATAXIA, TYPE 1 & KCNA1, ARG417TER \\
\hline .0013 & EPISODIC ATAXIA, TYPE 1 & KCNA1, THR226ARG \\
\hline .0014 & MYOKYMIA 1 & KCNA1, THR226LYS \\
\hline .0015 & MYOKYMIA 1 WITH HYPOMAGNESEMIA & KCNA1, ASN255ASP \\
\hline
\end{tabular}

\begin{tabular}{|c|c|c|}
\hline dbSNP & EXAC & ClinVar \\
\hline [rs104894352] & - & [RCV000014424] \\
\hline [rs104894348] & - & [RCV000014425] \\
\hline [rs104894349] & - & [RCV000014426] \\
\hline [rs104894356] & - & [RCV000014427] \\
\hline [rs104894357] & - & [RCV000014428] \\
\hline [rs104894353] & - & [RCV000014429] \\
\hline [rs104894354] & - & [RCV000014430] \\
\hline [rs104894355] & - & [RCV000014431] \\
\hline [rs267607195] & - & [RCV000014432] \\
\hline [rs28933381] & - & [RCV000014433] \\
\hline [rs28933382] & - & [RCV000014434] \\
\hline [rs104894358] & - & [RCV000014435] \\
\hline [rs28933383] & - & [RCV000014436] \\
\hline [rs28933383] & - & [RCV000014437] \\
\hline rs121918067] & . & [RCV000014438] \\
\hline
\end{tabular}

Figure 1.2.4.

Allelic variant table view showing dbSNP, ExAC, and ClinVar links 


\section{About Statistics - Downloads - Contact Us Editor Admin - MiMmatch - Donate - Help - 0}

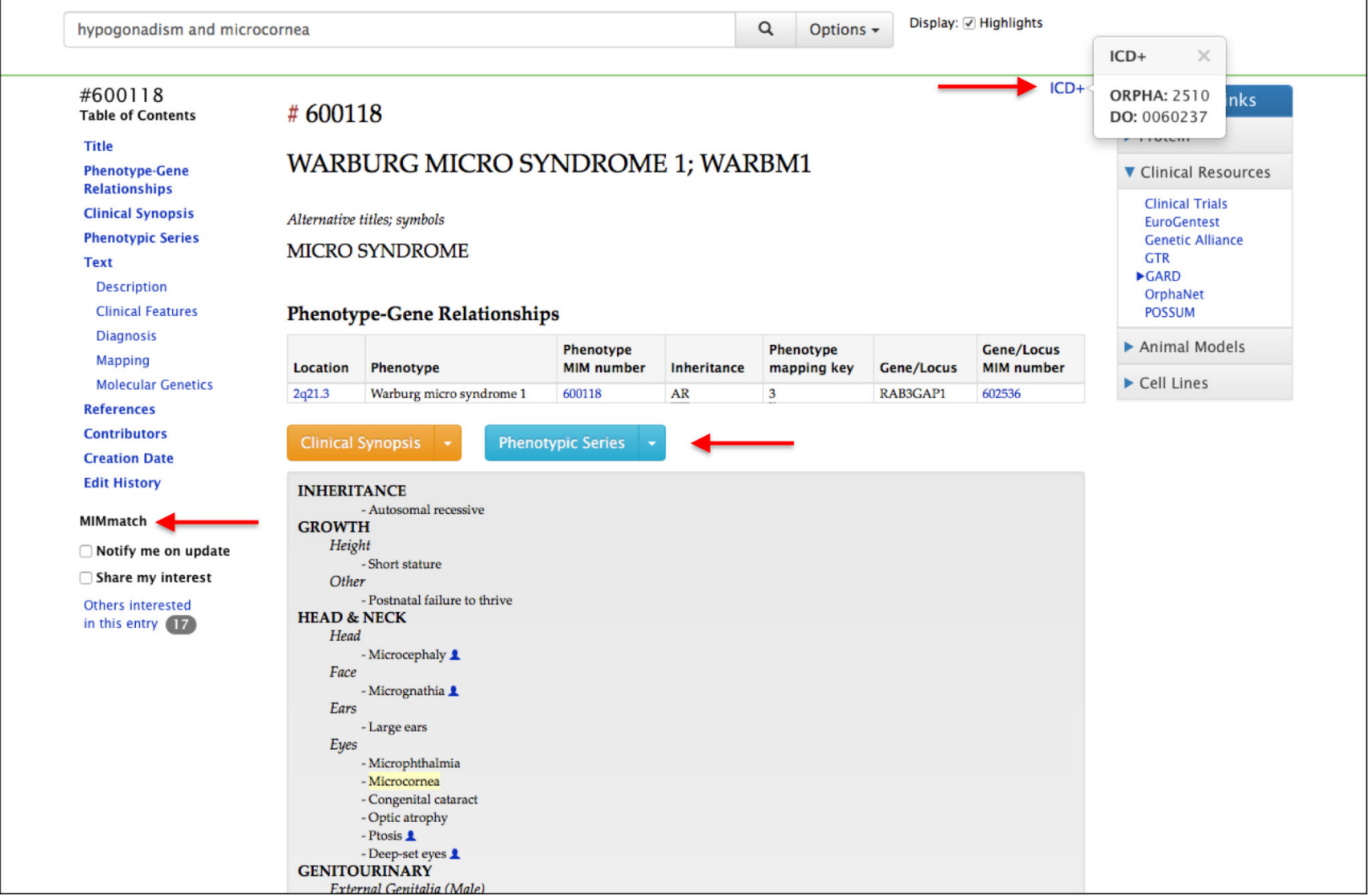

Figure 1.2.5.

Full view of entry 600118 showing the ICD+ coding numbers, in-page view of the clinical synopsis, and MIMmatch information. 
Phenotypic Series

Download As .

Warburg micro syndrome - PS600118 - 4 Entries

\begin{tabular}{|l|l|}
\hline Location & Phenotype \\
\hline $1 \mathrm{q} 41$ & Warburg micro syndrome 2 \\
\hline $2 \mathrm{q} 21.3$ & Warburg micro syndrome 1 \\
\hline $10 \mathrm{p} 12.1$ & Warburg micro syndrome 3 \\
\hline $20 \mathrm{p} 13$ & Warburg micro syndrome 4 \\
\hline
\end{tabular}

\begin{tabular}{|l|l|}
\hline Inheritance & $\begin{array}{l}\text { Phenotype } \\
\text { mapping key }\end{array}$ \\
\hline $\mathrm{AR}$ & 3 \\
\hline $\mathrm{AR}$ & 3 \\
\hline $\mathrm{AR}$ & 3 \\
\hline $\mathrm{AR}$ & 3 \\
\hline
\end{tabular}
MIM number 614225 600118

614222

615663

\begin{tabular}{|l|l|}
\multicolumn{2}{c}{ View corresponding clinical synopses as a table } \\
\hline Gene/Locus & $\begin{array}{l}\text { Gene/Locus } \\
\text { MIM number }\end{array}$ \\
\hline RAB3GAP2 & 609275 \\
\hline RAB3GAP1 & 602536 \\
\hline RAB18 & 602207 \\
\hline TBC1D20 & 611663 \\
\hline
\end{tabular}

Figure 1.2.6.

Phenotype Series for Warburg micro syndrome. The sort can be changed by clicking on the triangle links in the table headers. Explanation of the Inheritance and Phenotype mapping keys are available through a mouse-over pop-up. 


\section{About Statistics - Downloads - Contact Us Editor Admin - MiMmatch - Donate - Help - 0}

\begin{tabular}{|c|c|c|c|c|c|c|c|c|c|c|c|}
\hline \multicolumn{5}{|c|}{ +potassium +channel } & Q & Options - & \multicolumn{2}{|c|}{$\begin{array}{l}\text { View Results as: Entries } \\
\text { Display: } \nabla \text { Highlights }\end{array}$} & & & \\
\hline \multicolumn{12}{|c|}{ Search: '+potassium +channel (Entries with: gene map locus; Phenotype only entries; Retrieve: gene map)' } \\
\hline $\begin{array}{l}\text { Genomic } \\
\text { context } \\
\text { table }\end{array}$ & $\begin{array}{l}\text { Location } \\
\text { (from NCBI, } \\
\text { GRCh38) }\end{array}$ & Gene/Locus & \multicolumn{2}{|c|}{$\begin{array}{ll}\text { Show } 1001 \text { Download As - I \& First I } \\
\\
\text { Gene/Locus name } & \begin{array}{l}\text { GiM } \\
\text { MiM } \\
\text { number }\end{array}\end{array}$} & \multicolumn{2}{|c|}{ Phenotype } & $\begin{array}{l}\text { Phenotype } \\
\text { MIM } \\
\text { number }\end{array}$ & Inheritance & $\begin{array}{l}\text { Pheno } \\
\text { map } \\
\text { key }\end{array}$ & Comments & $\begin{array}{l}\text { symbol } \\
\text { (from } \\
\text { MGI) }\end{array}$ \\
\hline \multirow[t]{3}{*}{ 1: } & \multirow[t]{3}{*}{$\begin{array}{l}1: 2,019,328 \\
1 \mathrm{p} 36.33\end{array}$} & \multirow[t]{3}{*}{$\begin{array}{l}\text { GABRD, GEFSP5, EIG10, } \\
\text { EJM7 }\end{array}$} & \multirow[t]{3}{*}{$\begin{array}{l}\text { Gamma-aminobutyric acid } \\
\text { (GABA) A receptor, delta }\end{array}$} & \multirow[t]{3}{*}{137163} & \multicolumn{2}{|c|}{$\begin{array}{l}\text { [Epilepsy, juvenile } \\
\text { myoclonic, susceptibility } \\
\text { to) }\end{array}$} & 613060 & $\mathrm{AD}$ & 3 & & Gabrd \\
\hline & & & & & \multicolumn{2}{|c|}{$\begin{array}{l}\text { \{Epilepsy, idiopathic } \\
\text { generalized, 10\} }\end{array}$} & 613060 & $\mathrm{AD}$ & 3 & & \\
\hline & & & & & \multicolumn{2}{|c|}{$\begin{array}{l}\text { [Epilepsy, generalized, } \\
\text { with febrile seizures plus, } \\
\text { type 5, susceptibility to] }\end{array}$} & 613060 & $\mathrm{AD}$ & 3 & & \\
\hline 2: & $\begin{array}{l}1: 11,106,530 \\
1 \mathrm{p} 36.22\end{array}$ & MTOR, FRAP1, SKS & $\begin{array}{l}\text { Mechanistic target of } \\
\text { rapamycin }\end{array}$ & 601231 & \multicolumn{2}{|c|}{$\begin{array}{l}\text { Smith-Kingsmore } \\
\text { syndrome }\end{array}$} & 616638 & $\mathrm{AD}$ & 3 & & Mtor \\
\hline 3: & $\begin{array}{l}1: 16,021,990 \\
1 \mathrm{p} 36.13\end{array}$ & CLCNKA & $\begin{array}{l}\text { Chloride channel, kidney, } \\
\text { A }\end{array}$ & 602024 & \multicolumn{2}{|c|}{$\begin{array}{l}\text { Bartter syndrome, type } 4 b \text {, } \\
\text { digenic }\end{array}$} & 613090 & DR & 3 & $\begin{array}{l}11 \mathrm{~kb} \text { from } \\
\text { CLCNKB; } \\
\text { simultaneous } \\
\text { mutation in } \\
\text { CLCNKA } \\
\text { and } \\
\text { CLCNKB }\end{array}$ & Clankb \\
\hline \multirow[t]{2}{*}{ 4: } & \multirow[t]{2}{*}{$\begin{array}{l}1: 16,043,735 \\
1 \mathrm{p} 36.13\end{array}$} & \multirow[t]{2}{*}{ CLCNKB } & \multirow[t]{2}{*}{ Chloride channel, kidney, B } & \multirow[t]{2}{*}{602023} & \multicolumn{2}{|c|}{$\begin{array}{l}\text { Bartter syndrome, type } 4 \mathrm{~b} \text {, } \\
\text { digenic }\end{array}$} & 613090 & $\mathrm{DR}$ & 3 & \multirow{2}{*}{$\begin{array}{l}\text { unequal } \\
\text { crossingover } \\
\text { with } \\
\text { CLCNKA }\end{array}$} & \multirow[t]{2}{*}{ Clenka } \\
\hline & & & & & \multicolumn{2}{|c|}{ Bartter syndrome, type 3} & 607364 & AR & 3 & & \\
\hline
\end{tabular}

Figure 1.2.7.

OMIM Gene map with phenotype only view selected. 


\section{3) About Statistics - Downloads - Contact Us Editor Admin - MIMmatch - Donate - Help - 8}

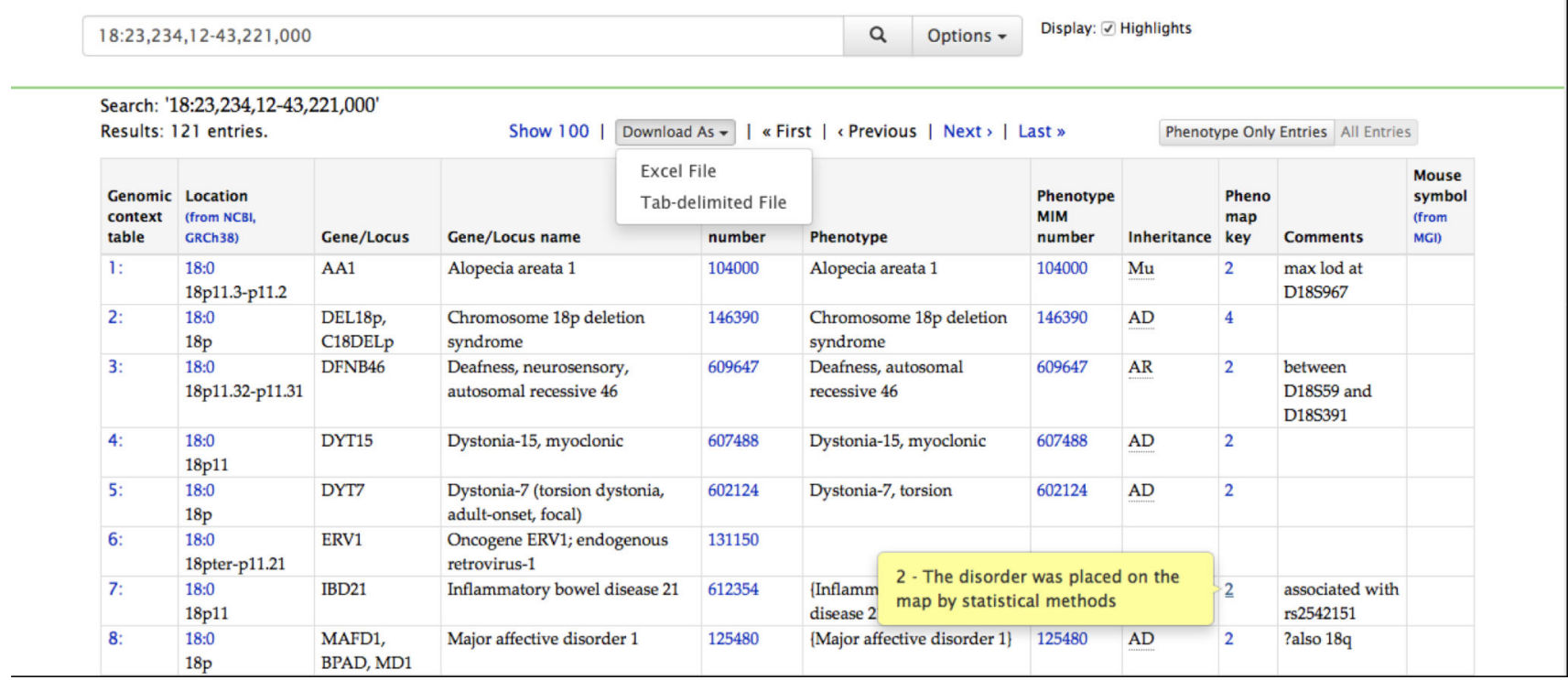

Figure 1.2.8.

OMIM Gene map results from a genomic coordinate search, 18:23,234,12-43,221,000. 


\section{About Statistics - Downloads - Contact Us Editor Admin - MIMmatch - Donate - Help - 0}

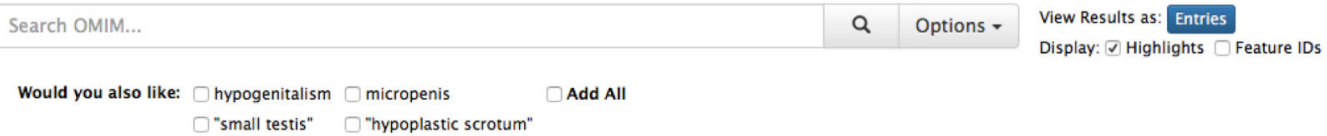

1: \# 600118. WARBURG MICRO SYNDROME 1; WARBM1

v Inheritance, Growth, Head \& Neck, Genitourinary, Skeletal, Skin, nails, \& hair, Neurologic, Molecular basis, Matching terms: hypogonadism, microcornea View full synopsis below View full synopsis on new page Links

2: \# 248800. MARINESCO-SJOGREN SYNDROME; MSS

Inheritance, Growth, Head \& Nec Skeletal, Nuscle, soft tissues, Neurologic, Endocrine features, Laboratory abnormalities, Miscellaneous, Molecular basis, Matching terms: - View full synopsi Skeletal deformities due to severe inks

3: \# 614222. WAF Kyphosis and hypotonia

- Inheritance, Grow Scoliosis letal, Skin, nails, \& hair, Muscle, soft tissues, Neurologic, Molecular basis, $\begin{array}{lll}\text { Matching terms: } & \text { Cubitus valgus } \\ \text { View full synopsi: } & \text { Coxa valga }\end{array}$

4. $\quad$ 212720. MAE Short metacarpals

4. \#212720. MAF Pes planovalgus

Inheritance, Grow Short metatarsals Molecular basis,

View full synopsis below View full synopsis on new page tunks

5: \# 615663. WARBURG MICRO SYNDROME 4; WARBM4

- Inheritance, Growth, Head \& Neck, Genitourinary, Skeletal, Skin, nails, \& hair, Muscle, soft tissues, Neurologic, Miscellaneous, Molecular basis, Matching terms: hypogonadism, microcornea

Figure 1.2.9.

Clinical Synopsis Quick View with feature mouse over the anatomical headings to pop-up the features. 
About Statistics - Downloads - Contact Us Editor Admin - MIMmatch - Donate - Help - 8

\begin{tabular}{|c|c|c|c|c|c|}
\hline \multicolumn{3}{|l|}{ Search OMIM... } & Options - & \multicolumn{2}{|c|}{ Display: $\square$ Feature IDs } \\
\hline NUMBER & $\# 234050$ & \#604168 & \# 212720 & & \# 600118 \\
\hline TITLE & $\begin{array}{l}\text { TRICHOTHIODYSTROPHY } 4 \text {, } \\
\text { NONPHOTOSENSITIVE; TTD4 }\end{array}$ & $\begin{array}{l}\text { CONGENITAL CATARACTS, FACIAL DYSMORPHISM, } \\
\text { AND NEUROPATHY; CCFDN }\end{array}$ & MARTSOLF S & NDROME & $\begin{array}{l}\text { WARBURG MICRO SYNDROME } 1 \text {; } \\
\text { WARBMI }\end{array}$ \\
\hline INHERITANCE & - Autosomal recessive & - Autosomal recessive & - Autosomal r & cessive & - Autosomal recessive \\
\hline \multirow[t]{3}{*}{ GROWTH 7} & & $\begin{array}{l}\text { Height } \\
\text {-Short stature }\end{array}$ & $\begin{array}{l}\text { Height } \\
\text {-Short s } \\
\text { - Height }\end{array}$ & $\begin{array}{l}\text { ature } \\
\text { less than } 5 \text { th percentile }\end{array}$ & $\begin{array}{l}\text { Height } \\
\text {-Short stature }\end{array}$ \\
\hline & & & $\begin{array}{l}\text { Weight } \\
\text {-Weight }\end{array}$ & less than $5 t$ & \\
\hline & $\begin{array}{l}\text { Other } \\
\text {-Growth retardation }\end{array}$ & & & & \\
\hline \multirow[t]{4}{*}{ HEAD \& NECK $\nabla$} & $\begin{array}{l}\text { Head } \\
\quad \text {-Microcephaly } 2\end{array}$ & & $\begin{array}{l}\text { Head } \\
\text { - Brachy } \\
\text { - Microc }\end{array}$ & $\begin{array}{l}\text { cephaly } 1 \\
\text { aphaly } 2\end{array}$ & \\
\hline & $\begin{array}{l}\text { Face } \\
\text {-Short smooth philtrum (rare) } \\
\text { - Retrognathia, mild (rare) }\end{array}$ & $\begin{array}{l}\text { Face } \\
\text { - Facial dysmorphism } \\
\text { - Prominent midface } \\
\text {-Thickening of perioral tissues } \\
\text { - Mandibular retrognathism }\end{array}$ & $\begin{aligned} & \text { Face } \\
& \text { - Mild } \mathrm{m} \\
& \text { - Microg } \\
& \text { - Short } \mathrm{p}\end{aligned}$ & $\begin{array}{lll}\text { axillary hy! } & \\
\text { nathia } 2 & \text { Further } \\
\text { hiltrum } 2 & \text { Morphol }\end{array}$ & $\begin{array}{l}\text { Further Information: Elements of } \\
\text { Morphology }\end{array}$ \\
\hline & $\begin{array}{l}\text { Ears } \\
\quad \text { - Large ears }\end{array}$ & & \multicolumn{2}{|c|}{$\begin{array}{l}\text {-Prominent antitragus } 1 \\
\text { - Posteriorly rotated ears }\end{array}$} & $\begin{array}{l}\text { Ears } \\
\quad \text { - Large ears }\end{array}$ \\
\hline & $\begin{array}{l}\text { Eyes } \\
\text { - Brittle and sparse eyebrows } \\
\text { - Brittle and sparse eyelashes } \\
\text { - Nystagmus (rare) } \\
\text { - Optic atrophy (rare) } \\
\text { - Epicanthal folds (rare) } \\
\text { - Microcornea (in some patients) } \\
\text { - Microphthalmia (rare) } \\
\text { - Nystagmus (in some patients) } \\
\text { - Infantile cataract (in some } \\
\text { patients) } \\
\text { - Decreased best corrected visual }\end{array}$ & $\begin{array}{l}\text { Eyes } \\
\text { - Congenital cataracts } \\
\text { - Microcorneas } \\
\text { - Nystagmus }\end{array}$ & \multicolumn{2}{|c|}{$\begin{array}{l}\text { Eyes } \\
\text { - Cataracts } \\
\text { - Epicanthal fold } 2 \\
\text { - Downward-slanting palpebral } \\
\text { fissures }\end{array}$} & $\begin{array}{l}\text { Eyes } \\
\text {-Microphthalmia } \\
\text { - Microcornea } \\
\text { - Congenital cataract } \\
\text { - Optic atrophy } \\
\text { - Ptosis } ~ \\
\text { - Deep-set eyes } ~\end{array}$ \\
\hline
\end{tabular}

Figure 1.2.10.

Clinical Synopsis Side-by-Side view with Elements of Morphology brachycephaly feature photo pop-up open. 


\section{About Statistics - Downloads - Contact Us Editor Admin - MIMmatch - Donate - Help - 8}

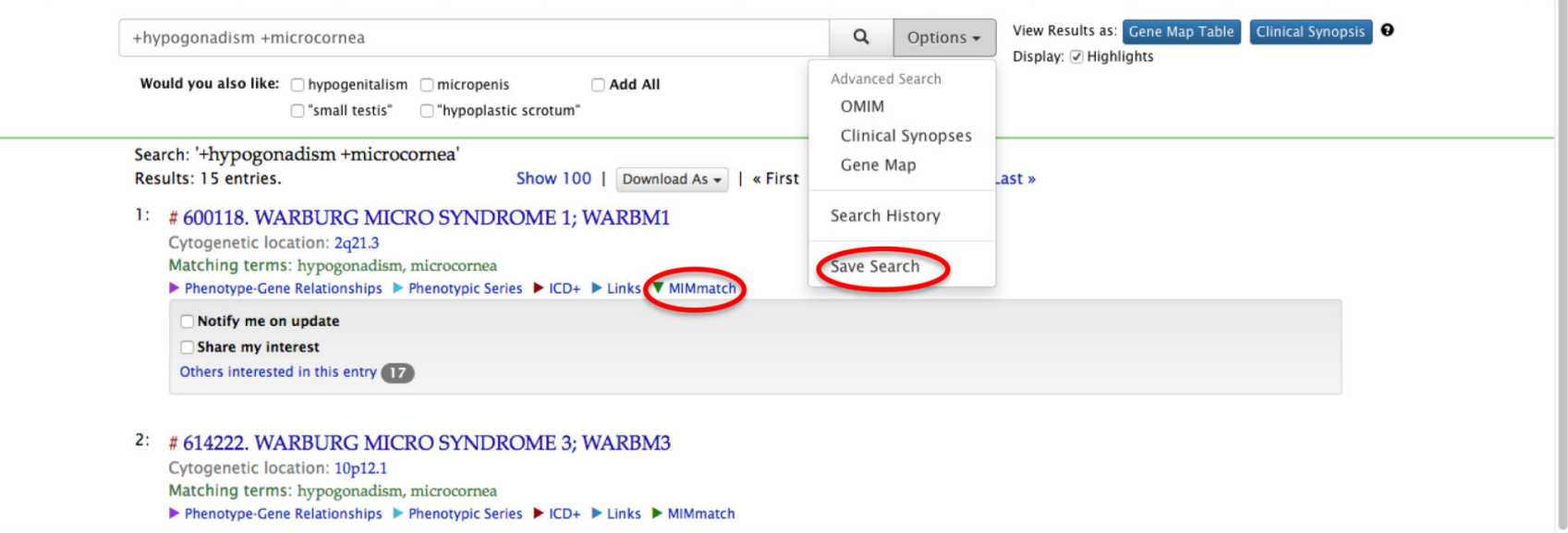

Figure 1.2.11.

MIMmatch options. 